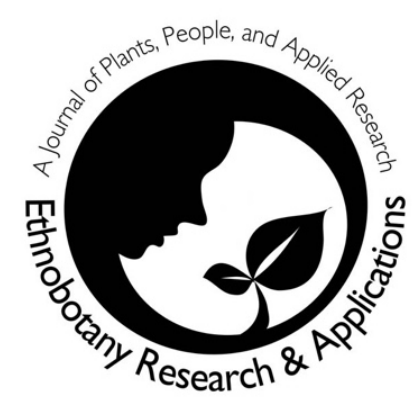

\title{
Bioculturalidade associada
} à extração e uso do azeite de uma etnovariedade de Sesamum L. (Pedaliaceae): Uma abordagem etnobotânica em uma comunidade rural no Semiárido do Piauí (Nordeste do Brasil)

Jorge Izaquiel Alves de Siqueira, Teresinha de Jesus Machado, Jesus Rodrigues Lemos

\section{Repatriation of ethnobotanical studies}

Repatriação de Pesquisas Etnobotânicas (Siqueira, J.I.A., Machado, T.J., Lemos, J.R. [2019]. Bioculturalidad Asociada a la Extracción y Uso del Aceite de una Etnovariedad de Sesamum L. (Pedaliaceae): Un Abordaje Etnobotánico en un Pueblo del Semiárido de Piauí [Noreste de Brasil]). Ethnobotany Research \& Applications 18(17):1-26.

\section{Resumo}

Antecedentes: A valorização e o resgate dos saberes empíricos em comunidades rurais de todo o planeta são elementos imprescindíveis à conservação da diversidade biocultural ao redor do mundo. A descrição e valorização dessas práticas bioculturais dentro da própria comunidade estudada deve ser considerada uma etapa do trabalho de todo pesquisador que maneje o tema de Etnobiologia. A comunidade rural Franco, município de Cocal, com localização no estado do Piauí (Nordeste do Brasil), passou por um desastre catastrófico há alguns anos, perdendo grande parte de sua área territorial. Apesar disso, uma pequena parte da comunidade se mantém ativa, conservando os costumes e práticas locais. Entre essas atitudes bioculturais, destacam- se as práticas que se baseiam no uso do azeite de "gergelim preto" (Sesamum indicum L. Pedaliaceae). Com o propósito de valorizar e resgatar essas práticas bioculturais, se apresenta um Photographic Essay, onde se documentam os usos do azeite da etnoespécie e a descrição das etapas de extração desse azeite.

Correspondence
Jorge Izaquiel Alves de Siqueira*
Jesus Rodrigues Lemos
Universidade Federal de Piauí (UFPI), Campus
Ministro Reis Velloso (CMRV), 64202-020,
Parnaíba, Piauí, BRASIL.
${ }^{*}$ Corresponding author: ethnosiqueira@gmail.com
Teresinha de Jesus Machado
Especialista local, Comunidade Rural Franco, Cocal,
64235-000, Piauí, BRASIL.
Ethnobotany Research \& Applications
19:11 (2020)


Métodos: Para a produção do Photographic Essay, levou-se a cabo uma investigação etnobotânica na comunidade rural Franco, região semiárida do Piauí, Nordeste do Brasil. Os dados etnobotânicos foram documentados a partir do uso da técnica de observação participante (convivendo com a comunidade) e aplicação de formulários semiestruturados.

Resultados: Localmente, o azeite de "gergelim preto" é utilizado como recurso medicinal (em sua maioria) e cosmético. O seu emprego se baseia em um conjunto de símbolos, crenças e práticas de cunho biocultural. No entanto, o conhecimento associado a essas práticas se encontra sob ameaça de desaparecimento, principalmente, pelo desinteresse entre os mais jovens e restrição dessas práticas a poucos residentes locais.

Conclusões: Os conhecimentos tradicionais associados à extração e uso do azeite de "gergelim preto" têm importância biocultural para a comunidade rural Franco. A valorização e o resgate dessas práticas são elementos essenciais e desempenham um importante papel para a manutenção da bioculturalidade associada, especialmente, em época de constantes ameaças a estes conhecimentos.

Palavras-chave: Bioculturalidade, resgate de saberes, ecologia biocultural, etnobiologia.

\footnotetext{
Abstract

Background: The valorization and rescue of traditional knowledge in rural communities of the whole planet are essential elements for the conservation of biocultural diversity around the world. The description and valorization of these biocultural practices within the studied community itself should be considered a stage of the work of every researcher who handles the topics of Ethnobiology. The Franco rural community, Cocal Municipality, located in the Piauí State (Northeastern Brazil), has suffered a catastrophic disaster a couple of years ago, losing a large part of its territorial area. Despite this, a small portion of the community remained active, conserving customs and local practices. Among these biocultural attitudes stand out the practices that are based on the use of "gergelim preto" oil (Sesamum indicum L.). With the purpose of evaluating and rescuing these biocultural practices, we present a Photographic Essay, where the uses of the oil of the ethnospecies, and the description of the extraction stages of this oil were documented.
}

Methods: The present ethnobotanical investigation was carried out in Franco rural community, Semiarid Region of Piauí State, Northeastern Brazil. The ethnobotanical data were documented from the use of the technique of participant observation (living with the community) and use of semi-structured interviews.

Results: Locally, "gergelim preto" oil is used as a medicinal resource (mostly) and as a cosmetic. Its application is based on a set of symbols, beliefs, and biocultural practices. However, the knowledge associated with these practices is under threat of disappearance, mainly due to the lack of interest among the younger generation and the restriction of these practices to few local residents.

Conclusions: The empirical knowledge associated with the extraction and use of "gergelim preto" oil presented a biocultural importance for the Franco rural community. The valorization and rescue of these practices are essential elements, and play an important role for the maintenance of the associated bioculturality, especially, in times of constant threats to this knowledge.

Key words: Bioculturality, rescue of knowledge, biocultural ecology, ethnobiology.

\section{Resumen}

Antecedentes: La valorización y rescate de las sabidurías empíricas en comunidades rurales de todo el planeta son elementos imprescindibles en la conservación de la diversidad biocultural alrededor del mundo. En cada comunidad, dichas prácticas de valorización y rescate deben ser consideradas pilares en el desenvolvimiento del investigador etnobotánico. La comunidad campesina Franco, en el municipio de Cocal, ubicada en el departamento de Piauí (Noreste de Brasil), sufrió una catástrofe por el aumento de las lluvias hace unos años, perdiendo así, gran parte de su área territorial. A pesar de esto, una pequeña parte de la comunidad se mantuvo activa, conservando las costumbres y prácticas locales. Entre esas actitudes bioculturales sobresale el uso del aceite de "gergelim preto" (Sesamum indicum L. - Pedaliaceae). Con el propósito de valorar y rescatar estas prácticas bioculturales, presentamos un Photographic Essay, donde son documentados los usos del aceite de la etnoespecie y la descripción de sus etapas de extracción.

Métodos: Para la producción del Photographic Essay, se llevó a cabo una investigación 
etnobotánica en la comunidad campesina Franco, Cocal, región semiárida de Piauí, Noreste de Brasil. Los datos etnobotánicos fueron documentados a partir del uso de la técnica de observación participante (conviviendo con la comunidad) y el uso de formularios semiestructurados.

Resultados: Localmente, el aceite de "gergelim preto" es utilizado como un recurso medicinal (en su mayoría) y como cosmético. Su aplicación se basa en un conjunto de símbolos, creencias y prácticas de carácter biocultural. Sin embargo, el conocimiento asociado a estas prácticas se encuentra amenazado y tiende a desaparecer, principalmente, por el desinterés entre los más jóvenes y la concentración de las prácticas en pocos residentes locales.

Conclusiones: Las sabidurías empíricas asociadas a la extracción y uso del aceite de "gergelim preto" tienen importancia biocultural para la comunidad campesina Franco. La valorización y rescate de estas prácticas son elementos esenciales y juegan un importante papel para el mantenimiento de la bioculturalidad asociada, especialmente, en época de constantes amenazas a estos saberes.

Palabras clave: Bioculturalidad, rescate de sabidurías, ecología biocultural, etnobiología.

\section{Antecedentes}

A comunidade rural Franco, localizada no município de Cocal, norte do Piauí, Nordeste do Brasil, perdeu grande parte de sua extensão no ano de 2009, durante $\mathrm{o}$ catastrófico rompimento da Barragem "Algodões l", gerando grandes impactos de carácter social, econômico, biológico e cultural. Apesar disso, uma pequena área (porção mais alta da comunidade em termos de relevo e em alguns pontos das encostas das superfícies aplainadas, dissecadas em interflúvios tabulares) da comunidade se manteve ativa, com pessoas vivendo nesses espaços, conservando os costumes e práticas locais. Devido a que o homem é um ser biocultural (Morin 1980), estas atitudes bioculturais (comportamento construído da interação entre traços biológicos e culturais, ver Siqueira 2018), tornam evidentes as relações entre os moradores locais e as plantas, os quais dependem direta e/ou indiretamente das matas ou dos quintais para obter seus recursos vegetais: combustível, alimento, remédios oriundos de plantas, construção, tecnologia, uso ornamental, místico-religioso, entre outros usos comuns na região (Siqueira \& Lemos 2016, Siqueira et al. 2017).
Estas inter-relações entre os moradores da comunidade rural Franco e as plantas podem ser compreendidas desde uma perspectiva etnobotânica. Na literatura científica, se registra uma diversidade de conceitos para o termo Etnobotânica, os quais variam entre os pesquisadores, dependendo de suas orientações epistemológicas, teóricas e práticas. No entanto, há muitos pontos cruzantes entre eles. Para Hernández-Xolocotzi (1979), a Etnobotânica se centra no entendimento da relação homem-planta, tendo em conta os fatores ambientais (condições ecológicas) e culturais como elementos determinantes dessas inter-relações entre a espécie humana e o mundo vegetal.

Outros autores (Albuquerque 2005, Albuquerque et al. 2017) respaldam a ideia de que os fatores culturais e ambientais, assim como o conceito de plantas e o que é elaborado com elas pelas culturas viventes, bem como as inter-relações indiretas entre o homem e as plantas, constituem-se elementos importantes a se considerar no momento de entender as abordagens e/ou definição de Etnobotânica, ou seja, compreender as interrelações entre a espécie humana e as plantas desde o campo da Ecologia Biocultural (Albuquerque \& Hurrell 2010, Hurrell \& Albuquerque 2012).

Nessa perspectiva, na busca pelo entendimento dessas inter-relações entre comunidades humanas $\mathrm{e}$ as plantas no estado do Piauí, estudos etnobotânicos formais iniciaram-se possivelmente com o trabalho de Emperaire (1983), na caatinga do sudeste do Estado. Desde então, as investigações diversificaram-se em suas diferentes orientações e/ou enfoques etnobiológicos (e.g., Almeida-Neto et al. 2017, Chaves et al. 2017, Filho et al. 2017, Siqueira et al. 2017, Bastos et al. 2018, Silva et al. 2018, Vieira-Filho et al. 2018), os quais contribuem à valorização e resgate dos conhecimentos tradicionais no Estado. Apesar disso, muitas situações que fazem parte da rotina de comunidades rurais, frequentemente, são ignoradas ou pouco aprofundadas, como é o caso da descrição detalhada de práticas bioculturais e/ou como se dá a aprendizagem social/cultural de ditas práticas.

Considerando esse aspecto, o uso do registro fotográfico pode contribuir com a valorização e melhor compreensão da execução dessas práticas, tornando-se uma ferramenta de registro histórico e/ou de carácter biocultural para a área de estudo. Além disso, nesse contexto pode contribuir com as discussões em torno da aplicação do potencial econômico a outras comunidades, uma vez que ao detalhar os usos tradicionais, pode fomentar o bem 
viver de outras pessoas em diferentes partes do mundo, onde a(s) etnoespécie(s) esteja(m) disponível(is).

Nesse sentido, interessantes práticas bioculturais sobre o uso do azeite de "gergelim preto" (Sesamum indicum L. - Pedaliaceae) são relatadas na comunidade rural Franco, sendo esta etnovariedade reconhecida a nível mundial como a planta oleaginosa mais antiga usada pelo homem (Arriel et al. 2009). Estes traços bioculturais sobre a espécie correm riscos de desaparecer se não se tomam as medidas adequadas para conservá-los, contribuindo a que possam seguir um padrão de transferência social/cultural ao longo das gerações, já que se encontram sob estado de ameaça.

Pelo anterior, objetivou-se documentar as práticas bioculturais e as etapas de extração do azeite de "gergelim preto" em uma comunidade rural em região semiárida do estado do Piauí a partir de uma abordagem etnobotânica, contribuindo à valorização e resgate dos conhecimentos tradicionais associados. Para isto, se apresenta um Photographic Essay, onde são descritas paisagens locais, áreas da comunidade, cultivo, etapas de extração do azeite, usos tradicionais e aprendizagem social/cultural associadas a $S$. indicum.

\section{Material e Métodos \\ Caracterização da área de estudo}

Para a sistematização e/ou produção do presente Photographic Essay, uma investigação etnobotânica foi conduzida na comunidade rural Franco (Fig. 1), pertencente ao município de Cocal $\left(03^{\circ} 28^{\prime} 15^{\prime \prime} S\right.$ 4133'18"O), norte do Piauí, Nordeste do Brasil. O município tem como população 26.036 habitantes e densidade demográfica de 20,51 hab./km² (IBGE 2010). Segundo a classificação de Köppen, o clima da região pertence aos domínios climáticos Aw' Tropical, caracterizados por um período de verão chuvoso e um período de inverno seco, com temperaturas mínimas e máximas de $25^{\circ} \mathrm{C}$ e $35^{\circ} \mathrm{C}$, respectivamente. Apresenta precipitação média anual de $900 \mathrm{~mm}$, registrando-se maior pluviosidade entre os meses de Março-Maio e, menores índices entre Julho e Dezembro (Medeiros 2004).
A vegetação local é caracterizada como vegetação de carrasco, apresentando transições vegetacionais fase caatinga hiperxerófila (vegetação caducifólia espinhosa) e/ou cerrado (vegetação de savana tropical) (Jacomine 1986, Chaves \& Barros, 2012). A comunidade Franco é essencialmente rural, os habitantes para sua subsistência vivem basicamente da agricultura e da criação de pequenos animais, muitos desses também praticam a caça de forma esporádica. Antes do rompimento da Barragem "Algodões l", se registrava a prática de pesca para a complementação da dieta proteica. Os moradores locais desenvolveram uma relação direta e de carácter biocultural com os quintais, espaços aos arredores das residências, onde cultivam uma alta diversidade de espécies, especialmente, como alimento e recursos medicinais (Siqueira \& Lemos 2016, Siqueira et al. 2017). Na região não há escolas, tampouco serviços públicos e/ou privados de saúde, apesar de que são acompanhados por um agente de saúde (para mais detalhes de paisagens e/ou áreas e rotina comumente registradas na comunidade Franco e próximo à Barragem "Algodões I", ver as Figuras 2-5).

\section{Procedimentos éticos e coleta de dados etnobotânicos}

O presente trabalho faz parte de um projeto de pesquisa mais amplo, o qual foi avaliado e aprovado (CAAE: 48893115.6.0000.5669) pelo Comitê de Ética em Pesquisa da Universidade Federal do Piauí (UFPI), Campus Ministro Reis Velloso (CMRV). O Termo de Consentimento Livre e Esclarecido (TCLE) foi assinado por todos os residentes locais que manifestaram interesse e concordância em participar da pesquisa (Brasil 2012). Para documentação dos dados, se procedeu com o uso de técnica de observação participante e/ou convivência com a comunidade (Bailey 1982) e aplicação de formulários semiestruturados (Martin 1995). As fotografias foram autorizadas, mediante o consentimento através da assinatura do Termo de Uso de Imagem, segundo a Resolução № 510 de 07 de Abril de 2016 do Conselho Nacional de Saúde (CNS) (Brasil 2016). A espécie foi coletada e identificada, seguindo as recomendações de Santos et al. (2014). O material botânico foi incorporado ao acervo do Herbário "Delta do Parnaíba - HDelta", da Universidade Federal do Piauí (UFPI/CMRV), registrado sob o Voucher 5252. 


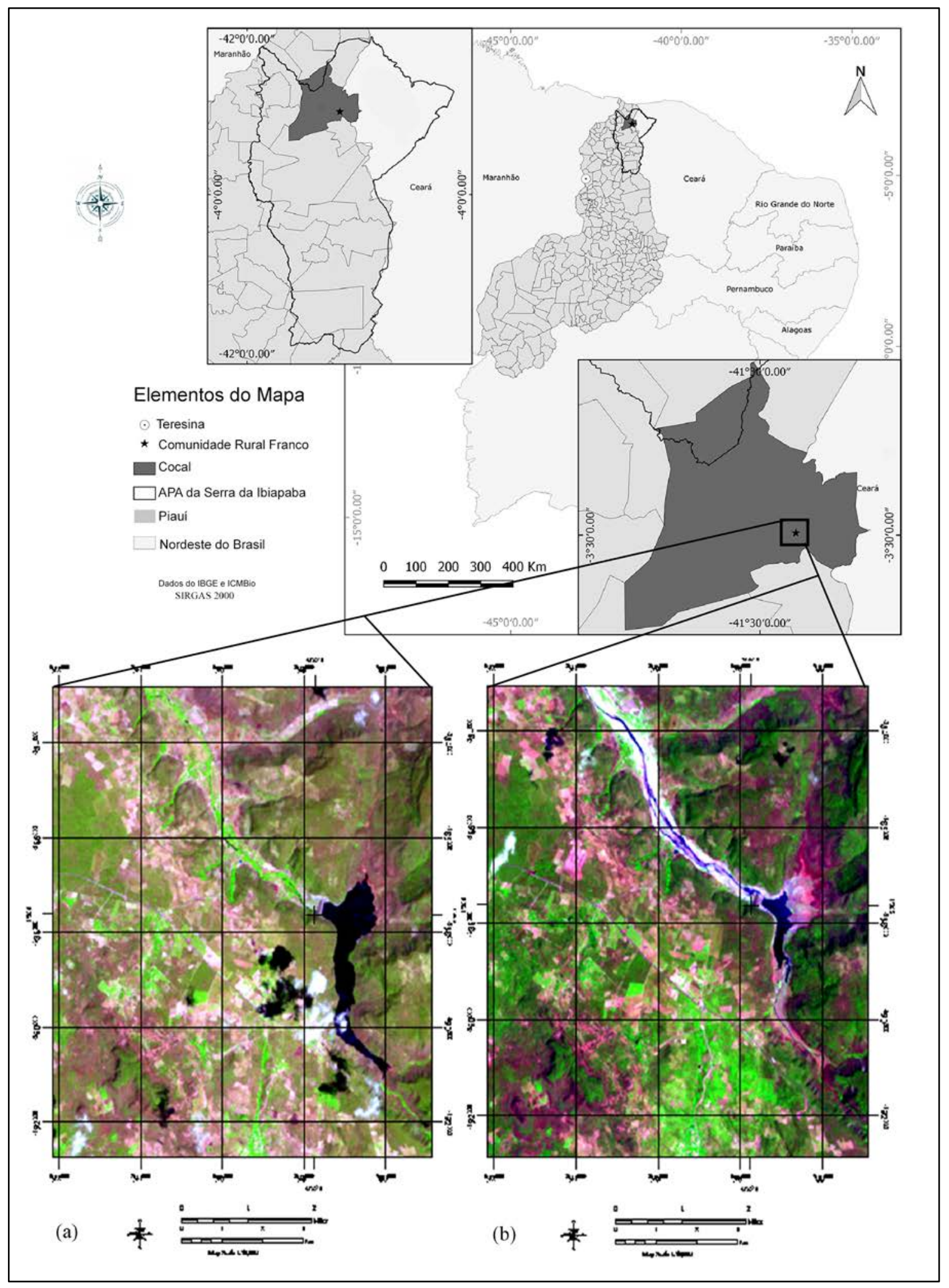

Fig. 1. Mapa de localização da comunidade rural Franco, Cocal, Piauí: em [a]. Espaços nos arredores e/ou próximos à comunidade Franco (ter como referência a Barragem "Algodões I", onde se observa a água) em 22/11/2008, antes da tragédia de "Algodões I", nessa data se registrava um maior volume de água na Barragem e maior área vegetacional; já em [b]. Registrava-se um reduzido volume de água na Barragem (09/11/2009) e grande parte da vegetação cedeu espaço a formações de areia. 


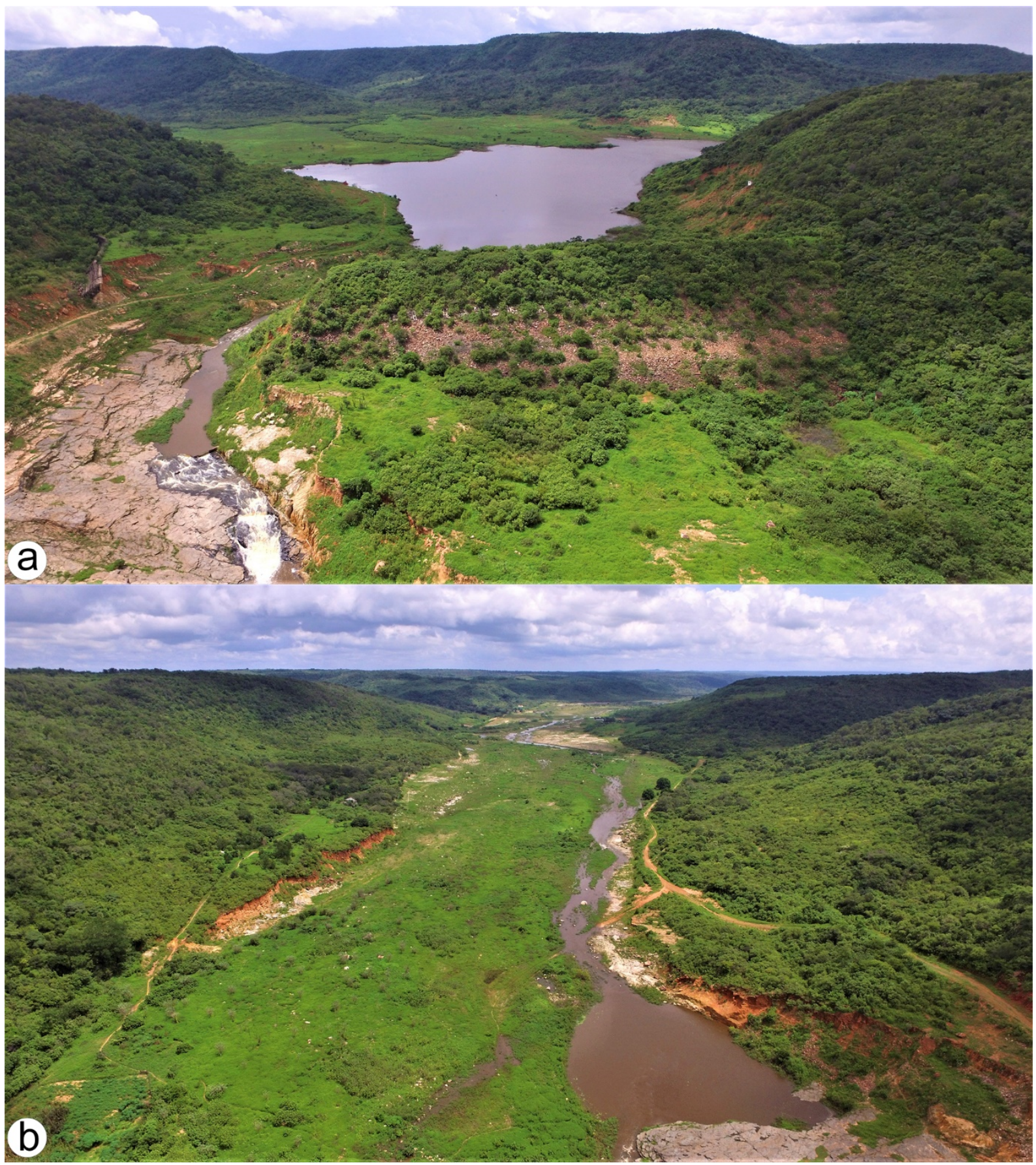

Fig. 2. Imagens atuais em áreas próximas ao que se mantém da Barragem "Algodões I": [a]. Vista da área atual da Barragem "Algodões I"; [b]. Toda esta área baixa da região, entre as superfícies aplainadas, dissecadas em interflúvios tabulares foi destruída durante a catástrofe de "Algodões I", onde viviam muitas famílias. 


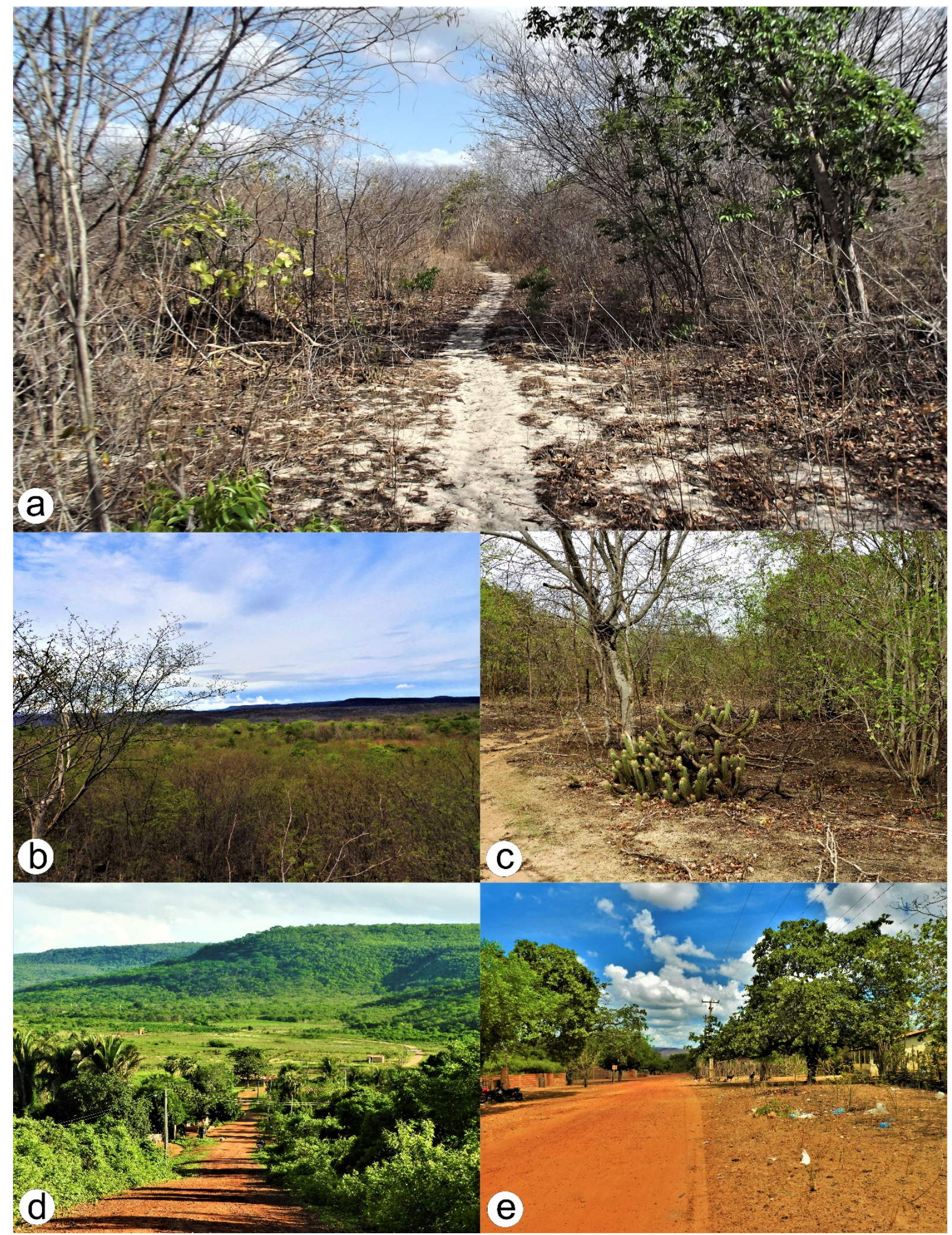

Fig. 3. Algumas paisagens registradas na comunidade rural Franco, Cocal, Piauí. [a]. Arredores das residências em época de seca, quando a maioria das plantas perdem suas folhas; [b]. Vista da vegetação presente em um quintal da comunidade; [c]. Paisagem comumente registrada na comunidade rural Franco; [d]. Região mais baixa da comunidade, em termos de relevo; [e]. Via que atravessa a comunidade rural Franco. 


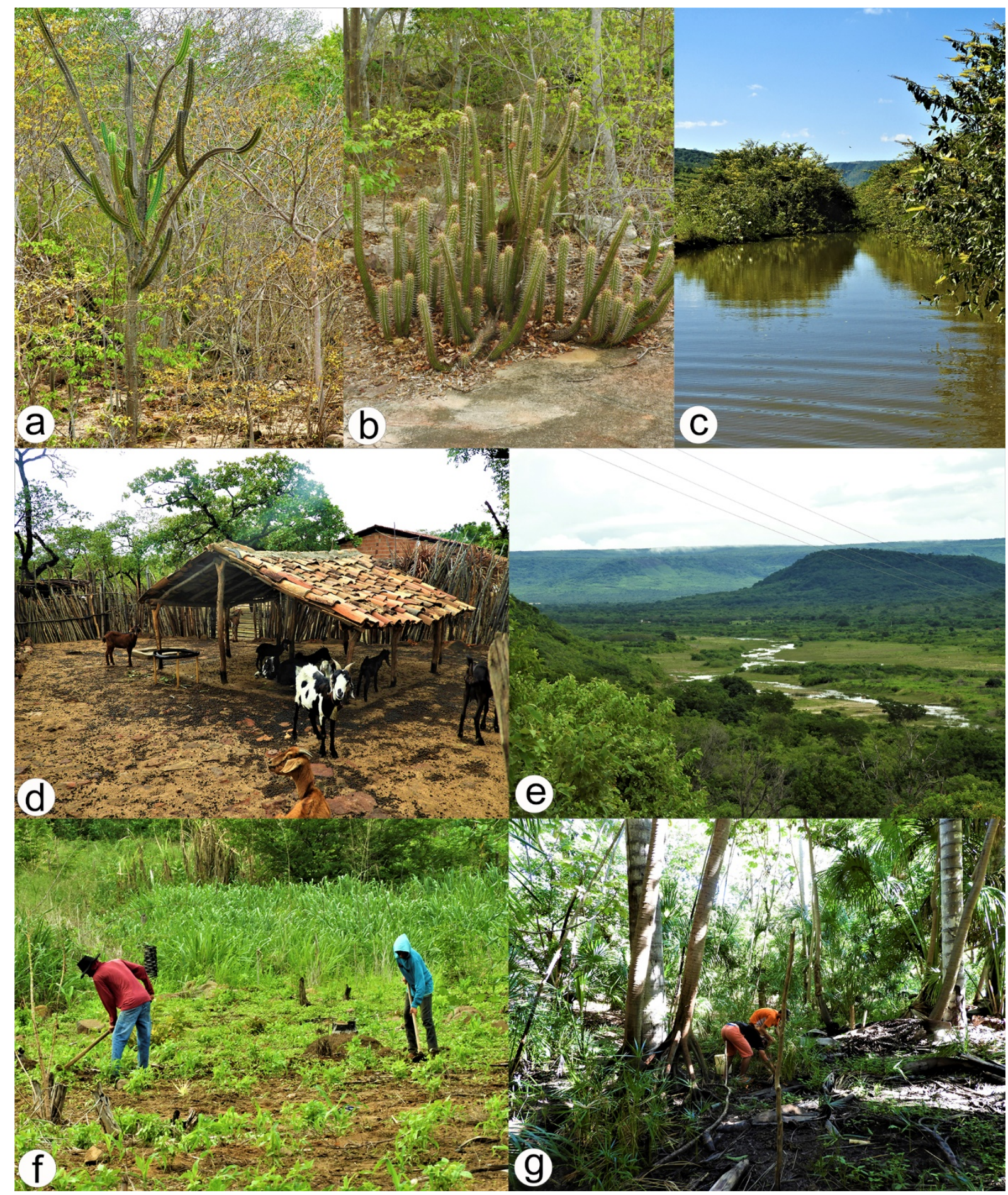

Fig. 4. Paisagens e rotina rural comumente registradas na comunidade rural Franco: [a-b]. Espécimes da família Cactaceae frequentes na comunidade; [c]. Área do Rio Piranji em época de cheia, onde os residentes locais a utilizam para lavar suas roupas e para lazer; [d]. Criação de cabras (Capra aegagrus Erxleben, 1777); [e]. Vista desde a Ladeira do Franco, onde se observa que a parte mais baixa (ter como referência o caminho paralelo ao rio) da comunidade foi destruída após o rompimento da Barragem "Algodões I" (2009); [f]. Agricultores trabalhando na carpina dos cultivos de "feijão" (Phaseolus vulgaris L.) e "milho"' (Zea mays L.) em um quintal; [g]. Residentes locais coletando frutos de "buriti" (Mauritia flexuosa L.f., Arecaceae). 

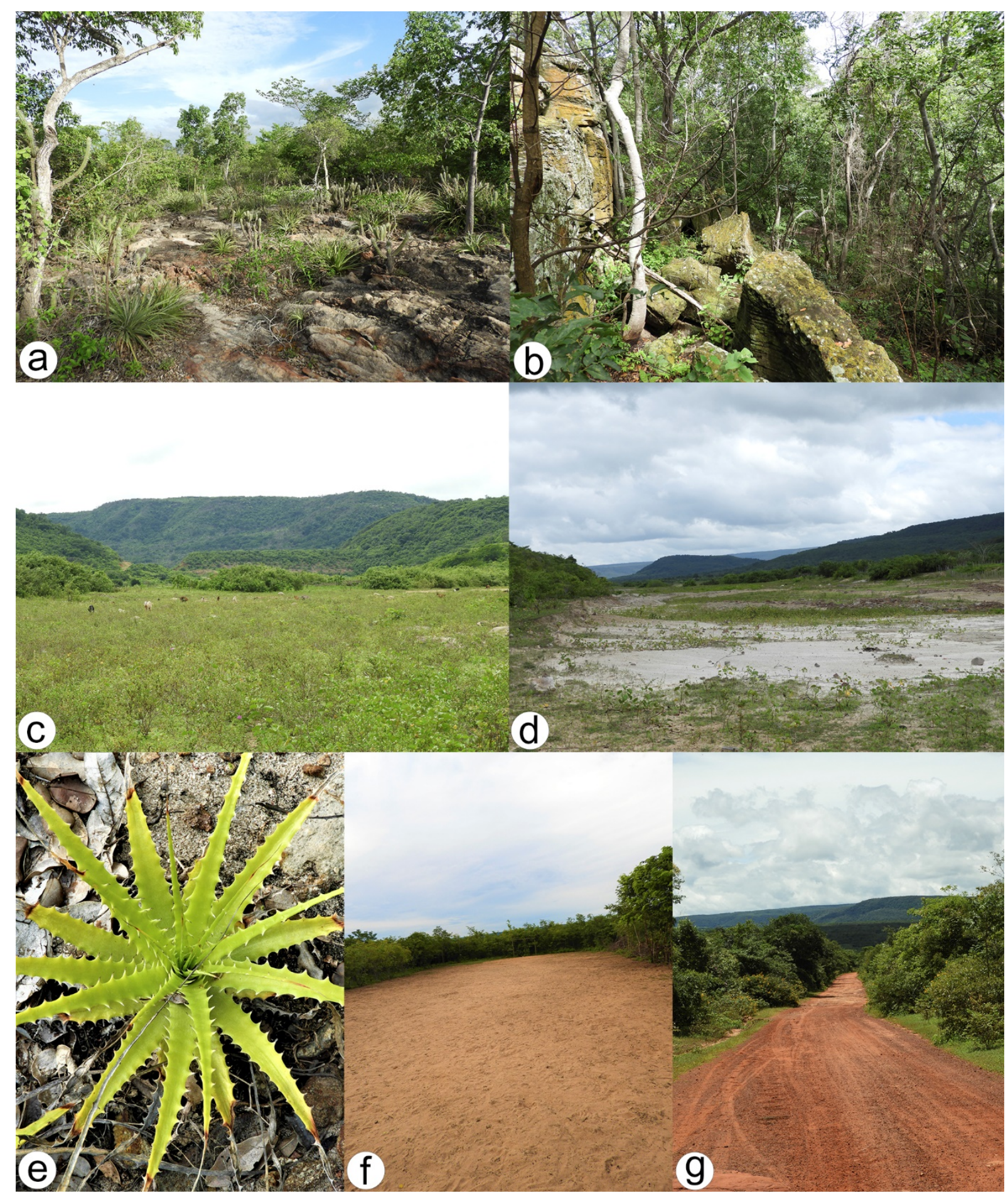

Fig. 5. Paisagens comumente registradas na comunidade rural Franco: [a]. Paisagem muito comum em áreas semiáridas do Brasil, onde muitas espécies vegetais crescem sobre as rochas; [b]. Vegetação típica no topo das superfícies aplainadas, dissecadas em interflúvios tabulares da comunidade (morros, denominação local); [c]. Área que que foi destruída pelo rompimento da Barragem "Algodões I", onde se registram muitas ervas e subarbustos; [d]. Outra área da comunidade destruída pela tragédia de "Algodões I", ao longo dessa área, na parte inferior, viviam muitas famílias; [e]. Espécie conhecida por "croatá" (Encholirium sp. - Bromeliaceae), na comunidade, seu registro é comum sobre as rochas ou nos arredores destas; [f]. Campo utilizado para recreação pelos moradores locais; [g]. Entrada da comunidade rural Franco. 


\section{Cultivo, crenças e descrição das etapas de extração do azeite}

\section{Cultivo}

A etnoespécie é cultivada nos quintais, nos meses de janeiro e fevereiro, períodos do ano preferidos para o cultivo, devido ao aumento das chuvas na região nesses períodos. Na maioria das vezes, o cultivo ocorre em áreas distantes das residências, onde uma porção da mata nativa é derrubada, da qual as folhas e galhos secam e depois são queimados (Fig. 6). O terreno queimado é limpo e posteriormente, em casos de chuvas, se dá o plantio das sementes. Em algumas ocasiões, quando acabam as sementes armazenadas de "gergelim preto" resultantes do cultivo nos quintais, essas são compradas. O volume de dois (2) litros é comprado

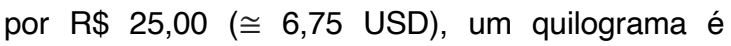
comprado por mais ou menos $R \$ 14-15$. A pequena garrafinha de azeite (Fig. 12d) é vendida por $R \$$ 40,00 ( 10,77 USD). Além do uso do azeite na comunidade, se registra um comércio externo para a compra desse produto, que já foi comercializado para diversos parte do país, desde maiores centros urbanos, tais como Fortaleza, algumas cidades do estado do Pará e no Distrito Federal (Brasília, DF.), até cidades menores, como Cocal dos Alves e comunidades rurais de Cocal.

\section{Crenças}

$\mathrm{Na}$ comunidade rural Franco se registram diversas crenças associadas à extração do azeite de "gergelim preto". Segundo os residentes locais, a lua pode influenciar no volume de azeite retirado. Mencionam que a lua em fase nova é o período mais indicado para executar a extração do azeite, a partir das sementes de $S$. sesamum (fotografias da espécie podem ser visualizadas na Fig. 7 a-b). Outras fases lunares não resultam produtivas em relação ao volume de azeite extraído. Os residentes locais não sabem explicar como a lua influencia na produtividade da extração do azeite, mas mencionam que por experiências próprias já comprovaram que a lua possui forte influência no processo de extração do azeite. Assim, a lua desempenha um importante papel na determinação do comportamento humano na execução dessa prática biocultural. Além disso, há um forte enraizamento de que nem todos podem observar o momento de extração do azeite, já que as pessoas que carregam "energias negativas" em caso de presenciar a produção do azeite, podem fazer com que o azeite desapareça e/ou que seu volume seja muito reduzido. Ainda, consideram que o volume do azeite pode varia a depender de quem seja o(a) responsável por fazer sua extração. Em linhas gerais, as pessoas mais experientes podem alcançar extrair um maior volume de azeite que pessoas menos experientes e com "energias negativas".

\section{Limpeza inicial, lavagem e secagem das sementes}

Antes de iniciar-se o processo de extração do azeite em si, as sementes passam por uma série de etapas, as quais asseguram sua limpeza (Fig. 8). Primeiramente, as impurezas e/ou corpos estranhos são retirados manualmente (Fig. $8 \mathrm{c}$ ) das sementes de "gergelim preto". Logo em seguida, passam por um processo de lavagem em oito águas, ou seja, as sementes são lavadas em oito vezes, até que a água resultante da lavagem não se veja tão escura (Fig. $8 d-g$ ). Depois desta etapa, as sementes são expostas à luz solar para sua secagem por aproximadamente quatro horas (Fig. 8j).

\section{Tostagem e maceração}

Nesta etapa as sementes são levadas ao fogo em uma panela grande durante mais ou menos 30-40 minutos, em que se deve mexer constantemente, evitando sua queima (Fig. 9a). O objetivo deste procedimento é permitir que as sementes percam água e desidratem, facilitando o trabalho na etapa de maceração (Fig. 9b-d). Depois da tostagem, deve-se macerar as sementes até que se forme uma massa homogênea, viscosa e/ou pegajosa (Fig. 10a).

\section{Fervura}

A mistura resultante da maceração deve ser levada ao fogo em lenha (Fig. 10b-c). Nesta etapa, se adicionam mais ou menos $3 \mathrm{I}$ de água à massa de "gergelim preto". A mistura deve ser mexida em intervalos curtos até que a porção menos densa (o azeite) fique na parte superior da mistura. À medida que a água sofra ebulição, deve-se repô-la, reestabelecendo seu volume. Esta etapa de fervura dura de 2-3 horas aproximadamente, dependendo do volume de sementes que foi macerado. 


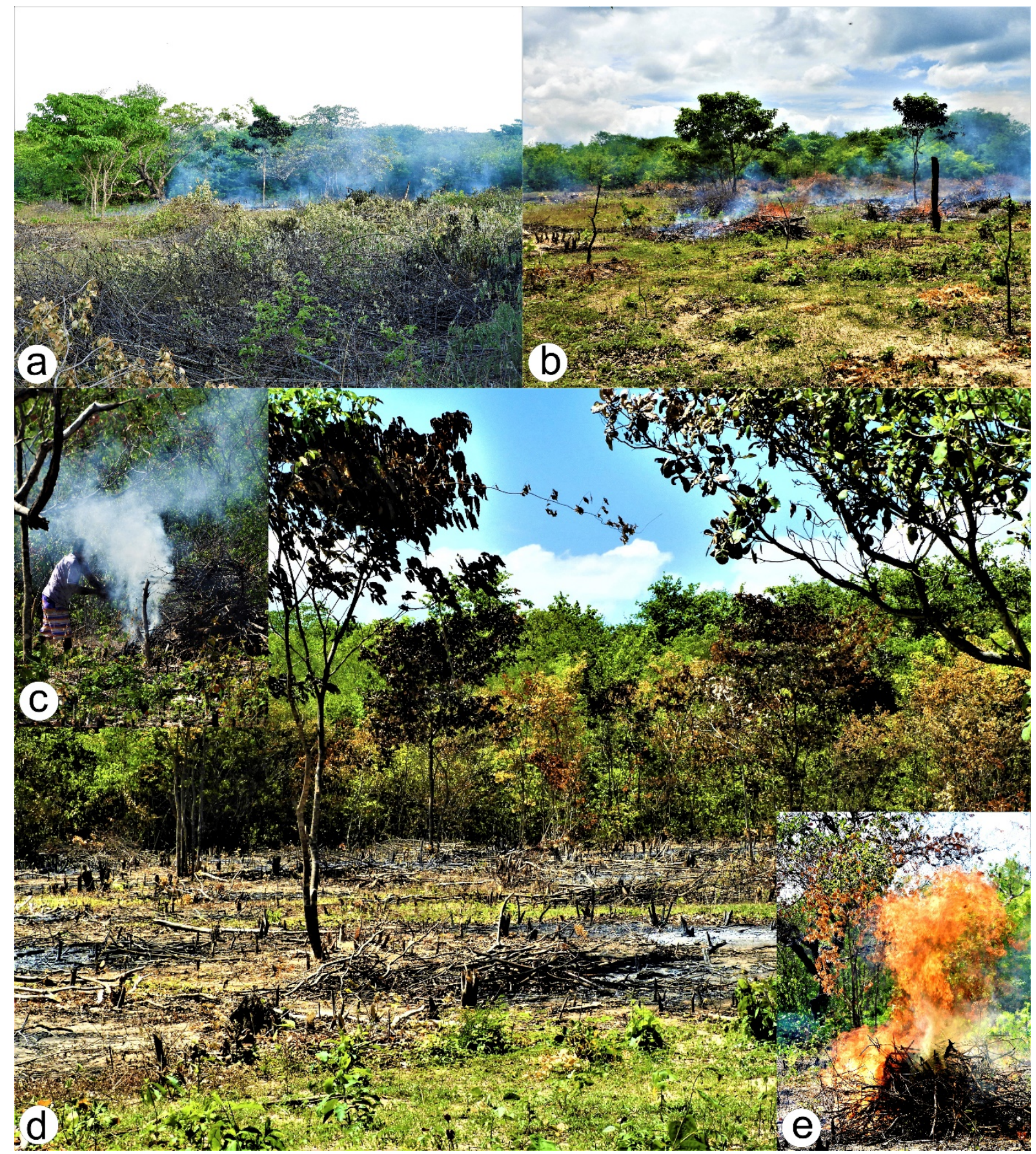

Fig. 6. Locais em que geralmente ocorre o cultivo de "gergelim preto" na comunidade rural Franco: [a]. A mata nativa é cortada, passa vários dias secando e depois é queimada; [b]. Folhagens e galhos secos em processo de queima; [c]. Residente local queimando a mata que foi derrubada; [d]. Área depois da queima; [e]. Fogo em madeiras que restaram da primeira queima. 


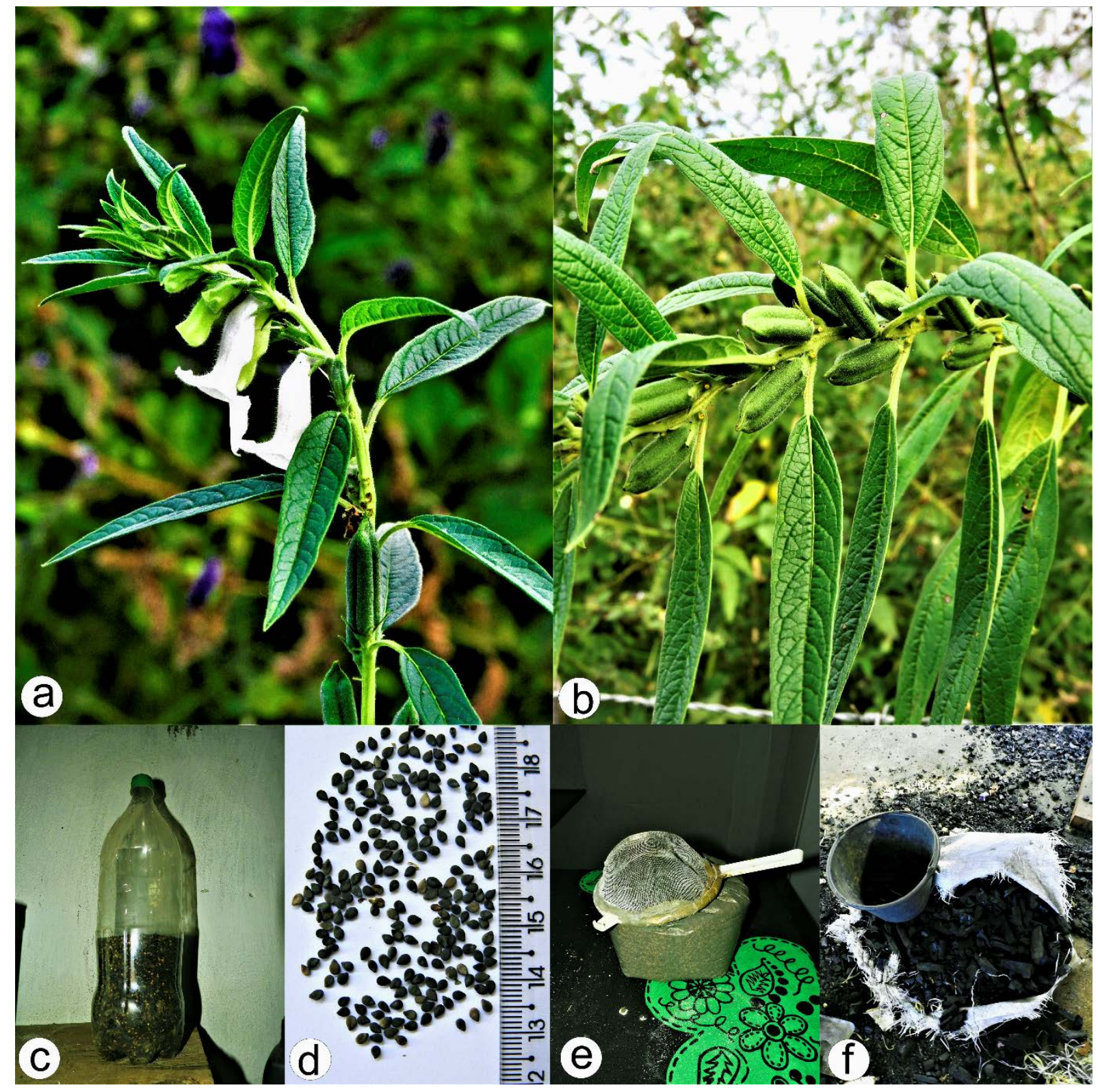

Fig. 7. Detalhes de $S$. indicum L. na comunidade rural Franco: [a]. S. indicum, evidenciando suas flores; [b]. $S$. indicum, evidenciando seus frutos; [c]. Sementes de S. indicum guardadas em garrafa PET por tempo indeterminado para posterior extração do azeite; [d]. Detalhes das sementes de $S$. indicum; [e]. Sementes de $S$. indicum armazenadas em sacola plástica, utilizada geralmente quando as sementes são compradas; [f]. Carvão vegetal, o qual é queimado durante algumas etapas da extração de azeite de $S$. indicum. 


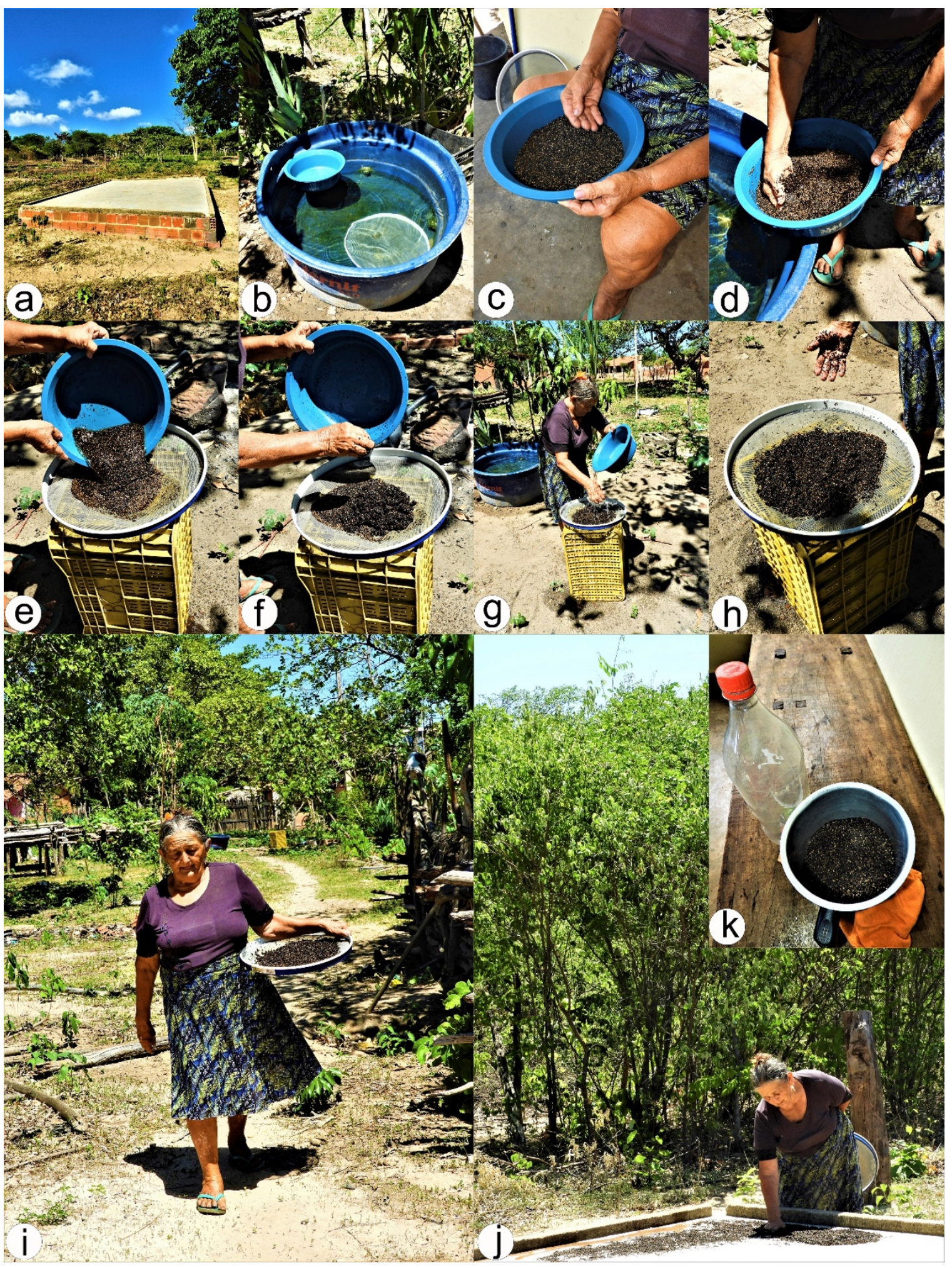

Fig. 8. Etapas de limpeza, lavagem e secagem das sementes de "gergelim preto": [a]. Local onde as sementes são expostas ao sol depois de sua lavagem; [b]. Água para a lavagem das sementes; [c]. Limpeza manual das sementes; [d-g]. Lavagem das sementes; [h]. Sementes após a lavagem; [i]. Especialista local com as sementes de "gergelim preto" lavadas, caminhando em direção ao local onde as sementes são postas a secar; [j]. Agricultora espalhando as sementes em uma área para facilitar sua secagem ao sol; [k]. Sementes após a secagem. 


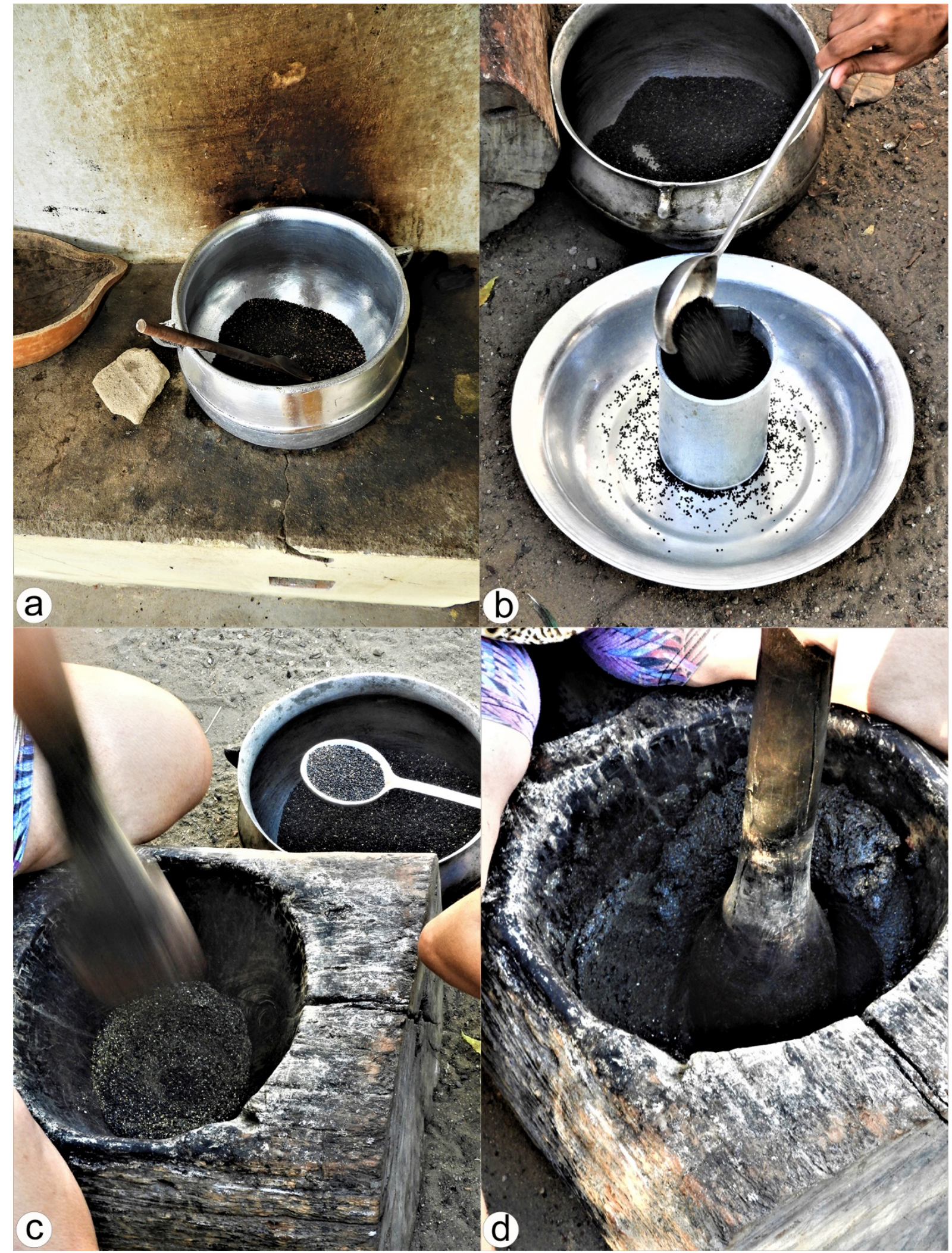

Fig. 9. Extração do azeite de "gergelim preto": [a]. Tostagem das sementes; [b]. Medição da quantidade de sementes a ser utilizadas na maceração inicial; [c]. Maceração inicial; [d]. Maceração após decorridos alguns minutos. 


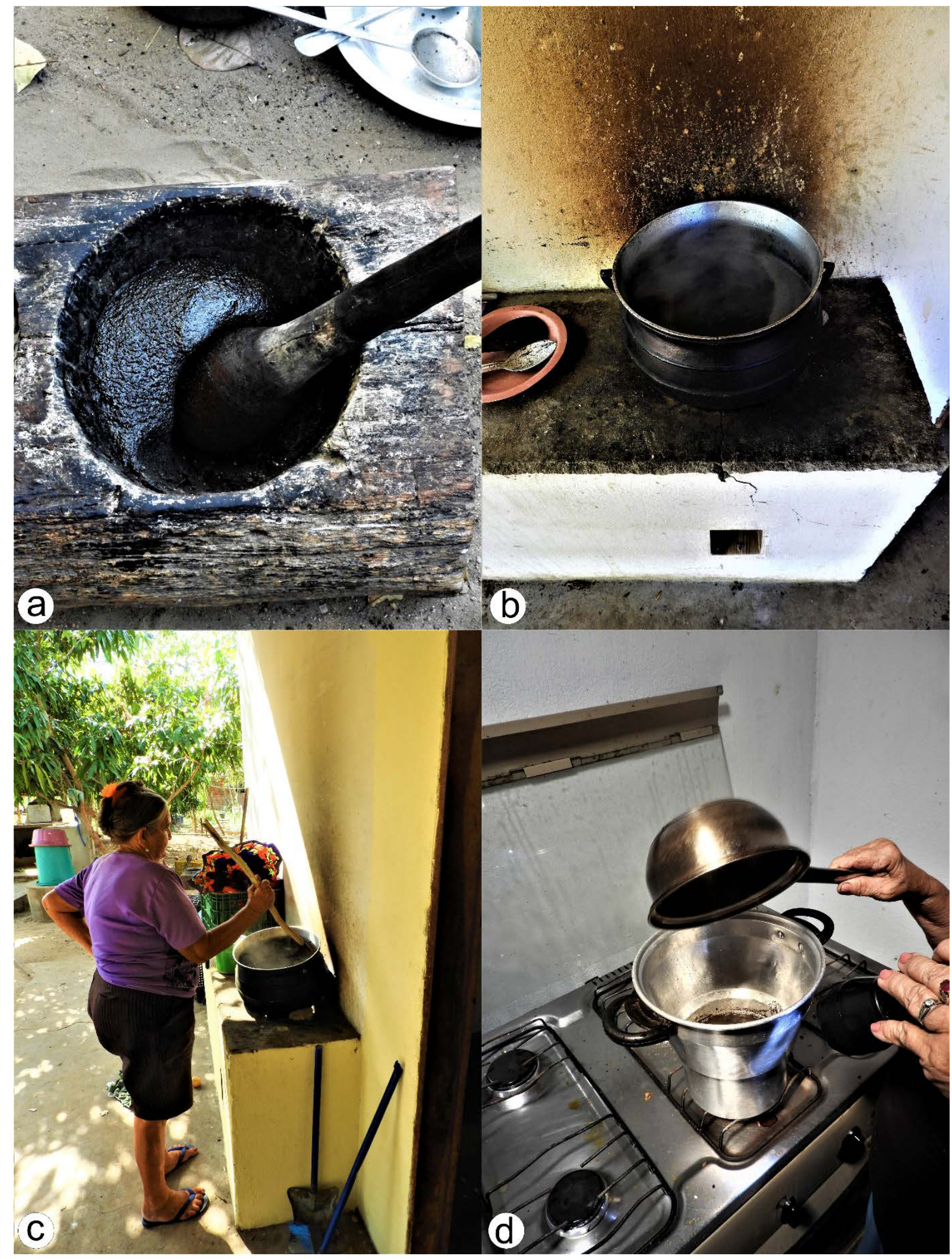

Fig. 10. Extração do azeite de "gergelim preto": [a]. Maceração final, formação de massa viscosa e/ou pegajosa; [b]. Fervura da massa resultante da maceração em fogão à lenha; [c]. Residente local mexendo a mistura em fervura; [d]. Fervura do sobrenadante para apuração do azeite em fogão a gás. 
pela etapa de apuração do azeite, ou seja, onde o azeite é concentrado (Figuras 10d e 11a). A finalidade desta etapa é fazer com que a água ainda restante sofra ebulição. Após a apuração, o azeite passa por um processo de filtragem em um pano de malha fina, onde as impurezas e/ou partículas sólidas são retidas, passando apenas a parte líquida da mistura.

\section{Esfriamento e etapa de envasilhar o azeite}

Depois do coamento do azeite, este necessita perder calor para ser armazenado. Por isso, passa por duas (2) etapas de esfriamento: 1) o recipiente contendo o azeite quente é posto sobre um pano de malha fina (Fig. 11b) y; 2) o azeite, todavia ligeiramente quente, é esfriado manualmente utilizando-se uma colher de ferro (Fig. 11c). Estas etapas de esfriamento duram em torno de 15-20 minutos. Finalmente, o azeite é envasilhado (armazenado) em pequenas garrafinhas PET e já se encontra pronto para ser utilizado (Fig. 12b-d). Na Figura 13 pode-se visualizar um fluxograma geral de todas as etapas de extração do azeite de "gergelim preto" na comunidade rural Franco.

\section{Usos tradicionais e aprendizagem social/cultural sobre 0 azeite de "gergelim preto" na comunidade rural Franco}

\author{
Usos tradicionais \\ $\mathrm{Na}$ comunidade rural Franco, o azeite de "gergelim \\ preto" é empregado para tratar diversos problemas \\ de saúde, ademais de ser utilizado como cosmético. \\ Entre esses, é utilizado para inchaço, inflamações, \\ terçol (Fig. 14), desfazer (diminuir e/ou acabar) \\ caroços gerais no corpo, problemas nos seios de \\ mulheres (caroço), sarar feridas, dores nas pernas e \\ joelhos. Para todos esses problemas mencionados, \\ o azeite é ligeiramente esquentado (amornado) e \\ misturado com sal. Logo em seguida, faz-se uma \\ massagem sobre a região e/ou parte do corpo em \\ que se quer cuidar e/ou tratar (Fig. 15). Deve-se \\ utilizá-la (a mistura de azeite e sal) duas (2) vezes
}

ao dia, cobrindo toda a região onde há o problema (se a ferida se encontra "aberta", somente se deve utilizar a mistura do azeite em seus arredores, jamais sobre a mesma). Para os tumores internos, o azeite é ingerido três (3) vezes ao dia durante sete (7) dias, a mesma receita é indicada para tratar gripe e infecções gerais. Como cosmético, uso não tão popular como o medicinal, se utiliza para hidratar o cabelo (misturado com um creme de hidratação de livre escolha). Os usos medicinais do azeite de "gergelim preto" são bem difundidos em toda a comunidade entre os residentes locais, devido à sua eficácia no tratamento e cura de enfermidades recorrentes localmente.

$\mathrm{Na}$ comunidade, o tratamento com azeite de $S$. indicum pode ser realizado de várias formas pelas quais é importante ressaltar que quando se fala de uso simultâneo nas linhas seguintes, nos referimos ao uso do azeite como a principal receita caseira que trata a enfermidade e/ou mal-estar diagnosticado. As quatro (4) formas de uso são: 1) unicamente o azeite ou em uma mistura com qualquer ingrediente, como o sal; 2) o uso simultâneo do azeite e o uso de medicamentos provenientes de drogarias e/ou farmácias; 3) o uso simultâneo do azeite e o uso de outra receita caseira, a partir de plantas locais que auxiliem e potencializem o tratamento (e.g., na comunidade utilizam uma decocção e/ou infusão em água fria das cascas do caule de Ximenia americana L. - Olacaceae, de nome local "ameixa", para ajudar no tratamento de inflamações, uma prática muito frequente localmente (Fig. 16) e; 4) o uso simultâneo do azeite e de práticas religiosas para acelerar o tratamento (e.g., benzeduras por parte de uma única curandeira [com 70 anos de idade] sobre a região e/ou área corporal a se tratar, uma prática que leva 35 anos de existência localmente). Estas práticas místico-religiosas não seguem um padrão de transferência social/cultural devido a que não é qualquer pessoa que pode executar estas práticas e atuar como curandeiro(a), somente aqueles(as) que recebem um dom de carácter espiritual para fazer isto. Assim, na comunidade rural Franco se registra um sistema de conhecimento e/ou médico biocultural híbrido formado por três configurações complementares e/ou alternativas (Fig. 17). 


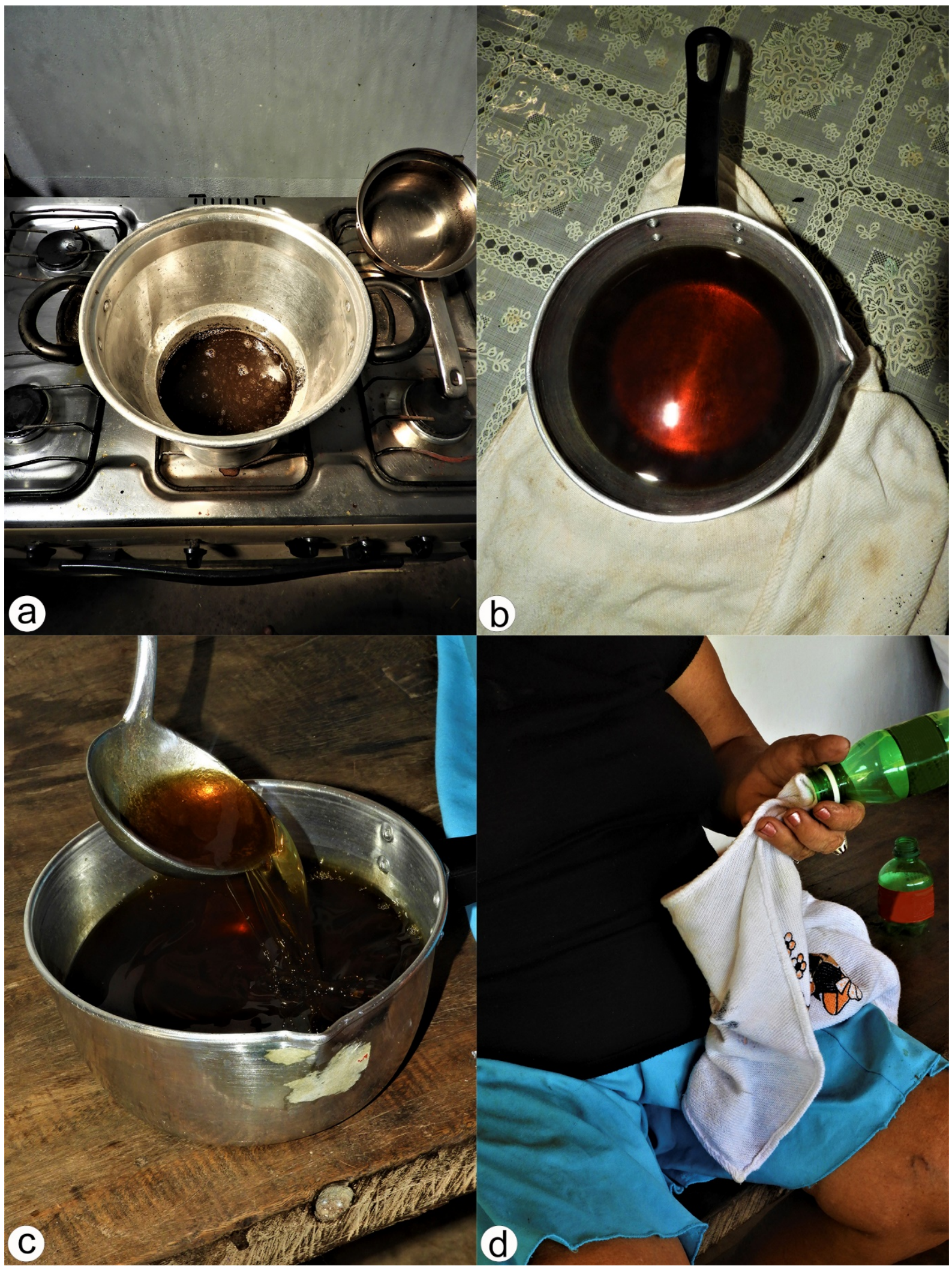

Fig. 11. Extração do azeite de "gergelim preto": [a]. O sobrenadante passa vários minutos em fervura para a apuração do azeite; [b]. Processo de esfriamento do azeite sobre um pano de copa; [c]. Esfriamento do azeite com o auxílio de uma colher; [d]. Limpeza e secagem de garrafinhas para o armazenamento do aceite. 


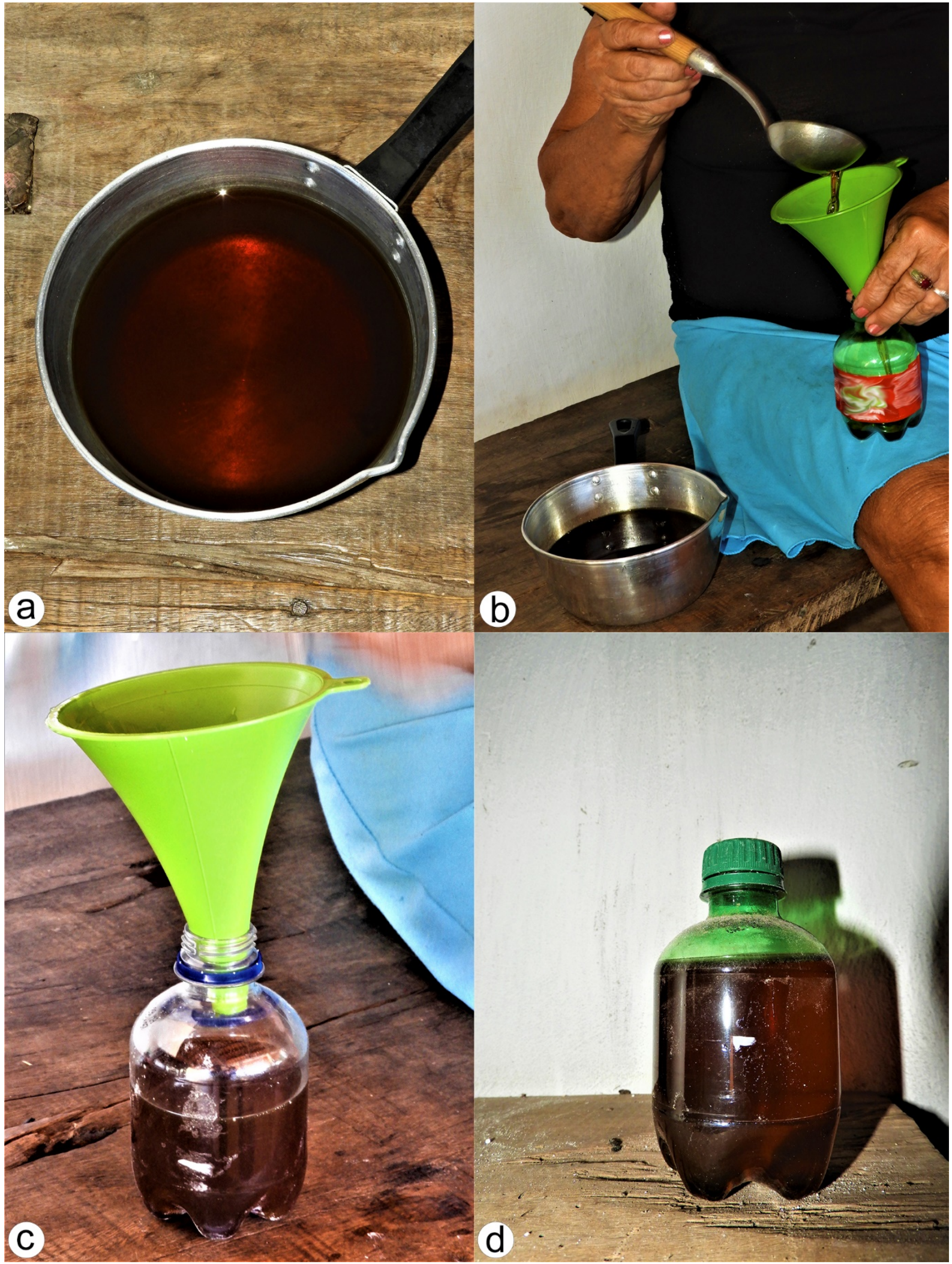

Fig. 12. Armazenamento do azeite de "gergelim preto": [a]. Azeite após o esfriamento; [b]. Etapa de armazenamento do azeite nas garrafinhas; [c]. Azeite transferido para a garrafinha; [d]. Azeite envasado e armazenado para usos em situações de emergência. 


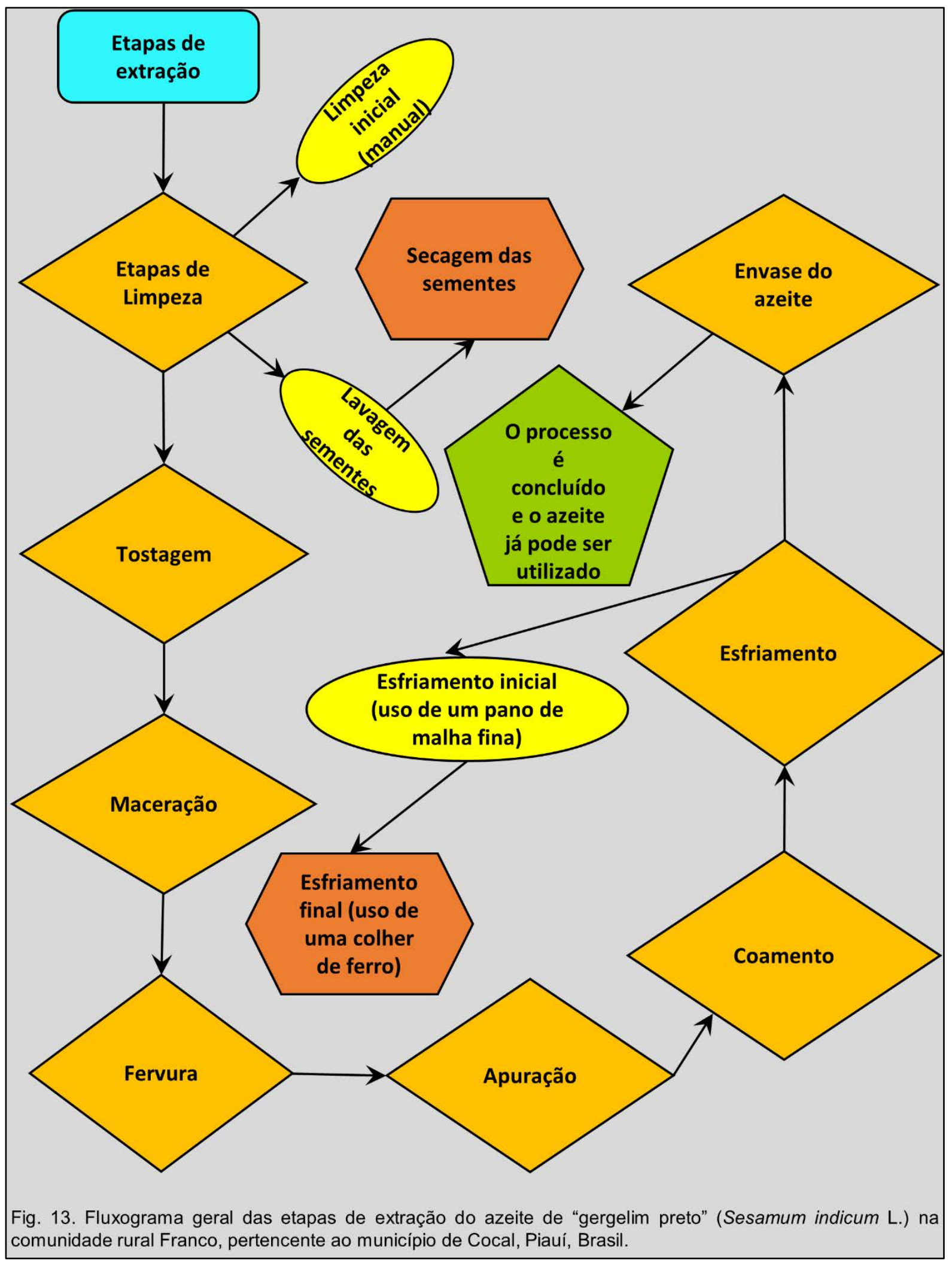




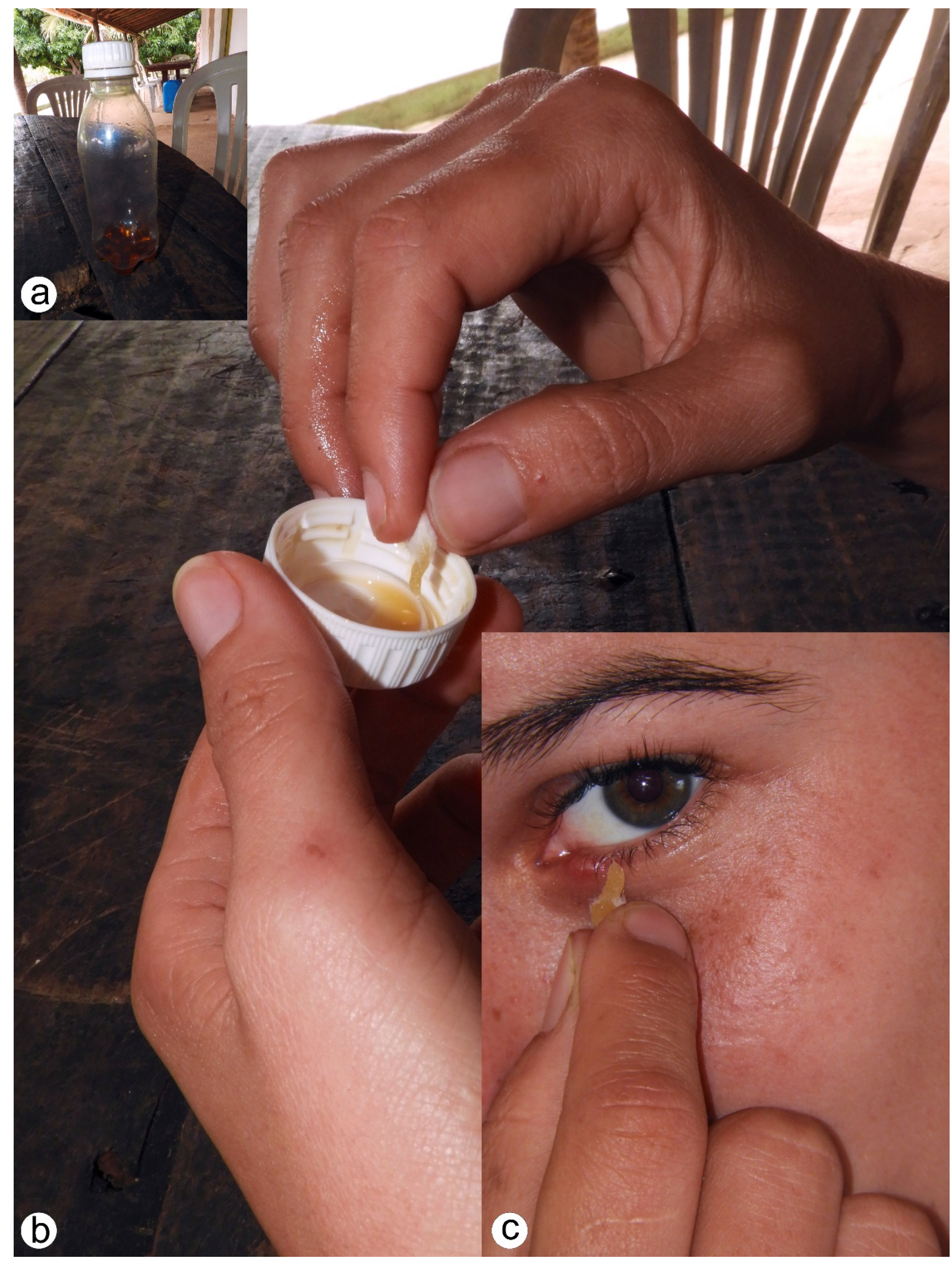

Fig. 14. Aplicação do azeite de "gergelim preto" para curar terçol: [a]. Garrafinha de azeite de "gergelim preto"; [b]. O azeite posto na tampa da garrafa para ser utilizado; [c]. Uso de um algodão embebecido em azeite para tratamento de terçol. 


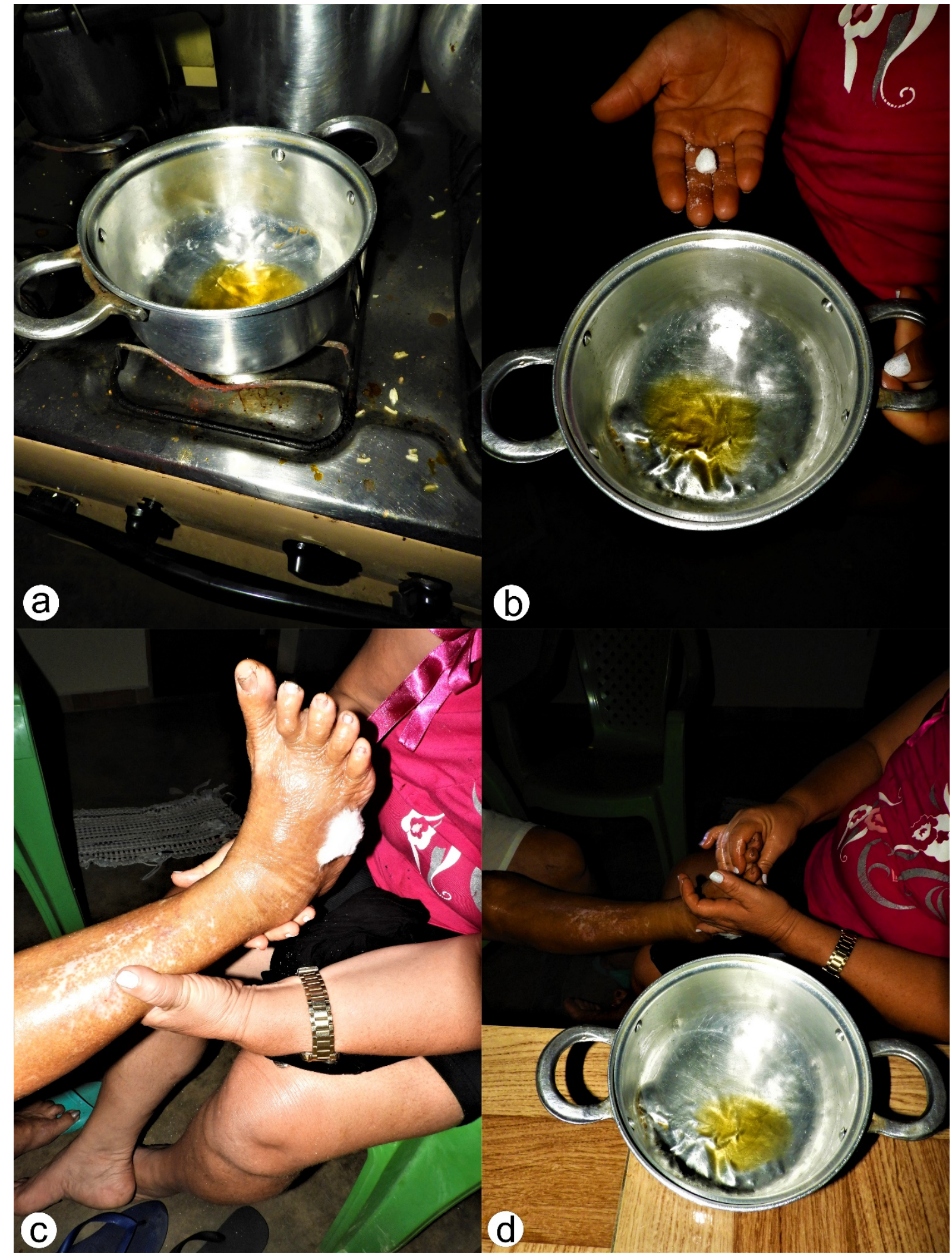

Fig. 15. Preparação e aplicação de remédio caseiro a partir do uso de azeite de "gergelim preto": [a]. Pequena quantidade de azeite esquentado ligeiramente (morno); [b]. Sal que será misturado ao azeite; [c]. Pé bastante inflamado de uma residente local; [d]. Aplicação da mistura de azeite e sal para tratar a inflamação no pé. 


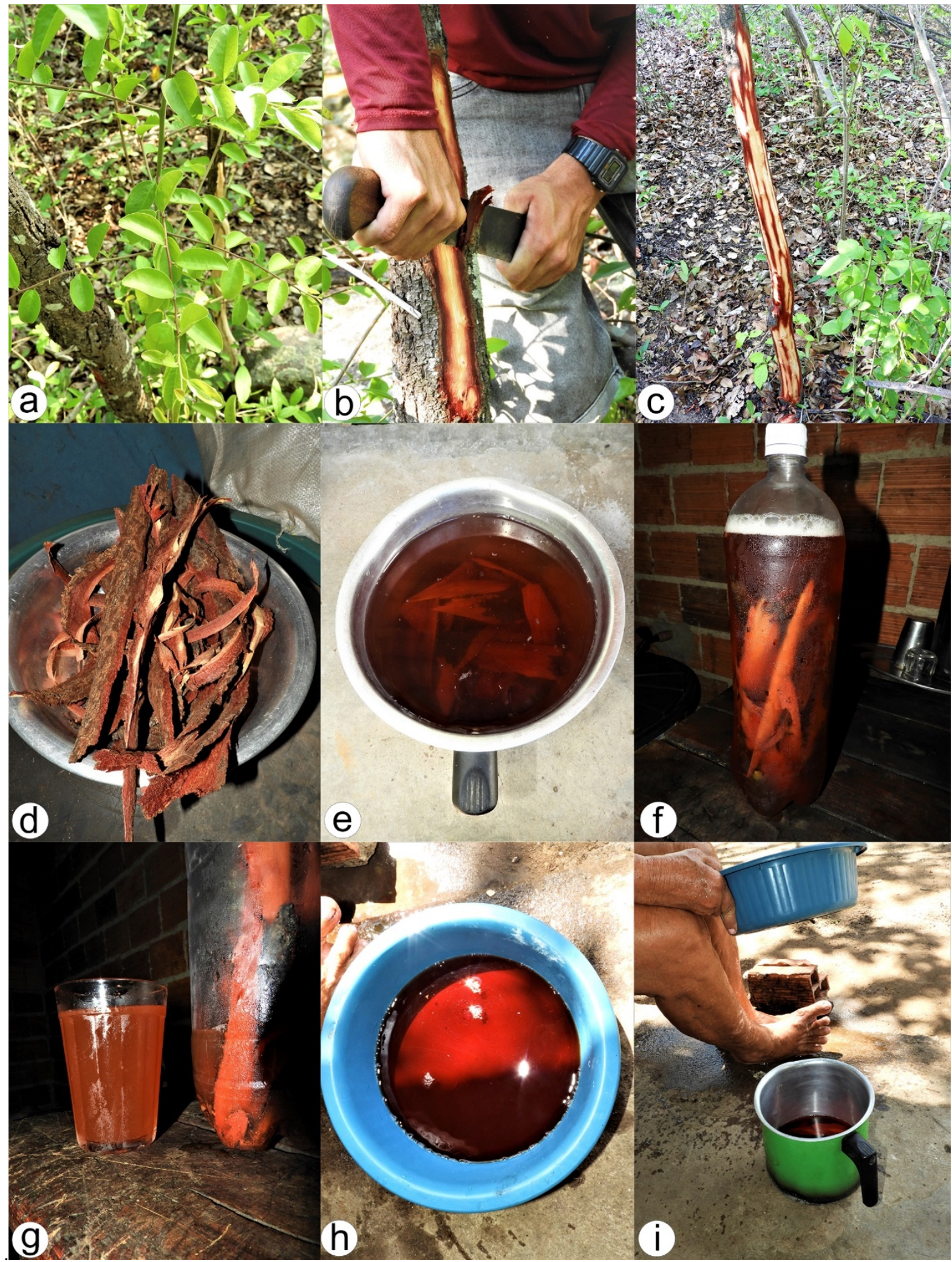

Fig. 16. Execução da prática biocultural relacionada ao uso da "ameixa" ( $X$. americana) na comunidade rural Franco: [a]. Detalhes de $X$. americana; [b]. Morador local coletando cascas do caule de $X$. americana; [c]. Caule de $X$. americana após a extração de cascas; [d]. Cascas do caule de $X$. americana após alguns dias de sua extração; [e]. Cascas do caule de $X$. americana postas em infusão em água (uso tópico); [f-g]. Infusão das cascas de $X$. americana em água fria, armazenadas em uma garrafa PET (uso oral); [h]. Mistura da infusão, a água fica bem avermelhada; [i]. Residente local fazendo a limpeza de seu pé (com uma infecção severa). 


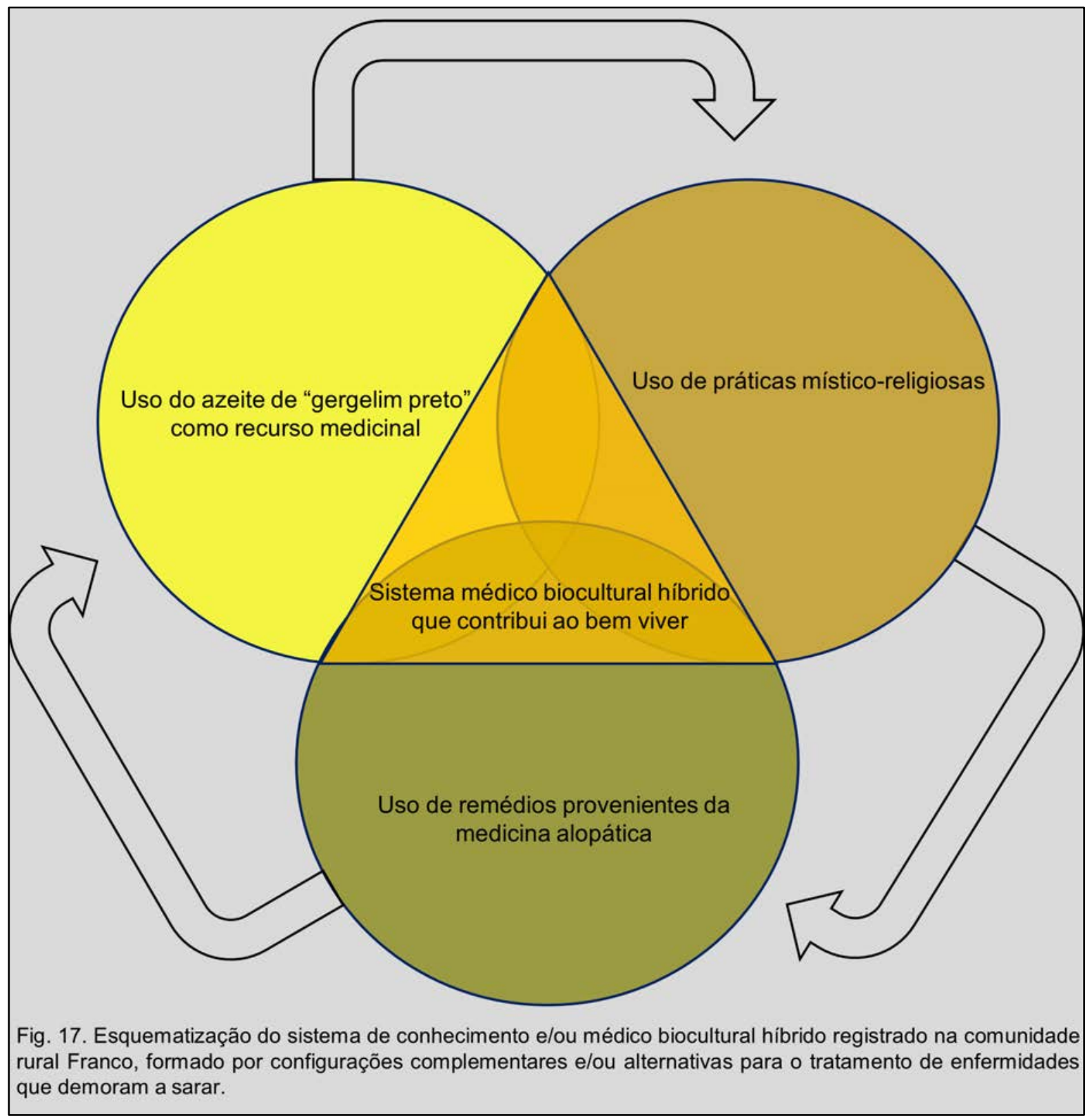

\section{Aprendizaje social/cultural}

\section{Aprendizagem social/cultural}

Com respeito à aprendizagem das práticas bioculturais, os principais participantes da pesquisa mencionam um número reduzido $(n=2)$ dos habitantes da comunidade que sabem realizar a extração do azeite. Isto está relacionado a que muitos deles não se interessam por esta atividade, devido ao grande esforço e tempo que a extração do azeite requer, ainda que reconheçam e/ou façam uso do azeite da espécie, principalmente, para fins medicinais. Nesta atividade, participa uma única especialista local da comunidade. A aprendizagem das práticas bioculturais na comunidade ocorre, em sua maioria, no âmbito familiar, de pais a filhos, com presença ativa dos mais idosos. Assim, se destaca o papel dos mais experientes na manutenção da bioculturalidade associada à prática de extração do azeite de "gergelim preto". É por isto que a aprendizagem social/cultural é mais intensa no contexto familiar, ainda que haja um intercâmbio de saberes entre vizinhos e pessoas provenientes de outras regiões.

Apesar da importância de aprendizagem desses conhecimentos, entre os fatores que ameaçam a manutenção dessas práticas na comunidade rural Franco, se enumeram: o forte desinteresse entre os mais jovens, sobretudo entre os residentes do gênero masculino, os quais creem que a prática de extração do azeite é tarefa da mulher e não é apropriada para eles, o contato com tecnologias modernas (como presença de Wi-fi em muitas residências da comunidade), o fluxo migratório e o 
registro do conhecimento sobre as práticas bioculturais associadas à etnoespécie restringido a poucos residentes locais, elementos que parecem atuar como barreiras para estabelecer o intercâmbio de saberes, contribuindo ao distanciamento e aumento do desinteresse por esses conhecimentos tradicionais.

\section{Considerações finais}

Os conhecimentos tradicionais associados à extração e uso do azeite de "gergelim preto" têm importância biocultural para a comunidade rural Franco. Localmente, o azeite é empregado para tratar diversos problemas de saúde, principalmente os que se relacionam a inflamações e, inclusive, como cosmético. Este acervo de conhecimentos involucra um conjunto de crenças, símbolos e práticas de natureza biocultural. A valorização e resgate dessas práticas são elementos importantes e/ou imprescindíveis para a manutenção da bioculturalidade associada (ver Siqueira 2018), especialmente, em época de constantes ameaças a estes conhecimentos.

O processo e as condições registradas para a extração do azeite de "gergelim preto" na comunidade rural Franco não asseguram sua qualidade e segurança em seus usos, especialmente, como recurso medicinal administrado de forma oral. Portanto, novos estudos que avaliem a qualidade do azeite usado localmente são necessários. E, desde então, que se possam desenvolver ações e/ou estratégias que contribuam ao melhor aproveitamento desse produto. Neste sentido, o treinamento e/ou qualificação das pessoas que realizam diretamente a extração desse produto poderia configurar-se como uma intervenção fundamental e de grandes efeitos positivos.

O sistema de conhecimento e/ou médico biocultural híbrido registrado na comunidade rural Franco não se encontra totalmente compreendido, novas investigações são necessárias para uma melhor compreensão e/ou entendimento sobre as configurações e fatores (variáveis sociais, ecológicas, ambientais e culturais) que levam à conformação e/ou estruturação deste sistema, gerando dados de grandes dimensões para o desenvolvimento de estratégias efetivas direcionadas à conservação, proteção e resguardo da diversidade biológica e cultural local.

Como forma de dar-lhe seus devidos méritos, fato respaldado por sua grande colaboração ao longo de toda esta pesquisa, uma agricultora especialista em plantas medicinais e na flora local da comunidade Franco é coautora do presente manuscrito. Apoiamos a ideia apresentada por Ramirez (2007) em que "existe uma necessidade de dar-lhes, não somente com reconhecimentos, mas também como coautores de nossas publicações na mesma forma em que incluímos estudantes ou colaboradores acadêmicos que nos ajudam em campo ou em laboratório". Devido a seu formato (Photographic Essay), o presente manuscrito apresenta algumas limitações, como a ausência de uma discussão detalhada de nossos achados na literatura científica, tendo em conta que em um Photographic Essay as fotografias devem falar por si.

\section{Declarações}

Lista de abreviaturas: CAAE (Certificado de Apresentação para Apreciação Ética), CNS (Conselho Nacional de Saúde), PET (Tereftalato de Polietileno).

Aprovação ética e consentimento para participar: Todos os participantes outorgaram seu consentimento prévio informado antes da presente investigação etnobotânica.

Consentimento para a publicação: Todas as pessoas que aparecem em imagens deste documento estiveram de acordo com a publicação das fotografias. Todos os autores revisaram e aprovaram a versão final do presente manuscrito.

Disponibilidade de dados e materiais: Não se aplica.

Interesses em Competência: Não se aplica.

Financiamento: Não se aplica.

Contribuição dos autores: JIAS = Concepção, desenho da pesquisa, coleta de dados, fotografias (com exceção da Figura 2, que é de autoria de "DJ Ricardo Imagens Aéreas", reproduzida com permissão do autor) e escrita do manuscrito; TJM = Compartilhou e/ou socializou importantes conhecimentos de natureza biocultural para que fosse possível a sistematização e organização deste documento; JRL = Coordenação da pesquisa e revisão do manuscrito.

\section{Agradecimentos}

Os autores são gratos à toda a comunidade rural Franco, pela receptividade e atenção brindadas ao longo de toda a pesquisa. À Universidade Federal do Piauí (UFPI/CMRV) pela possibilidade de uso de 
sua infraestrutura, especificamente do Laboratório de Botânica e pela Bolsa de Iniciação Científica Voluntária (ICV) concedida ao primeiro autor. Ao "DJ Ricardo Imagens Aéreas" pela permissão para reprodução da Figura 2. Ao Prof. Dr. Johnson Fernandes Nogueira (UFPI/CMRV) pela amabilidade e atenção ao longo da seleção e tratamento das imagens "a" e "b" da Figura 1.

\section{Literatura citada}

Albuquerque UP. 2005. Introdução à Etnobotânica. $2^{\mathrm{a}}$ Ed. Interciência, Rio de Janeiro.

Albuquerque UP, Hurrell JA. 2010. Ethnobotany: one concept and many interpretations. Recent developments and case studies in Ethnobotany. Editado por UP Albuquerque, $\mathrm{N}$ Hanazaki. SBEE/NUPEEA, Recife, Pp. 87-99.

Albuquerque UP, Ramos MA, Ferreira Júnior WS, Medeiros PM. 2017. Ethnobotany for Beginners. Springer Briefs in Plant Science, Gewerbestrasse, Switzerland.

Almeida-Neto JR, Santos KPP, Silva MEC, Morais RF, Costa Neto EM, Silva PRR, Barros RFM. 2017. Conhecimento sobre uso de plantas repelentes e inseticidas em duas comunidades rurais do Complexo Vegetacional de Campo Maior, Nordeste do Brasil. Gaia Scientia 11(1):210-224.

Arriel NHC, Beltrão NEM, Firmino PT. 2009. O produtor pergunta, a Embrapa responde. Embrapa Informação Tecnológica, Brasília, DF, Brasil.

Bastos EM, Silva MEC, Vieira FJ, Barros RFM. 2018. Conhecimento botânico local em uma área de assentamento rural no Piauí, Nordeste do Brasil. Gaia Scientia 12(2):12-33.

Brasil. 2012. Conselho Nacional de Saúde, Resolução N 466, de 12 de Dezembro de 2012. Diário Oficial da União, Brasília, Brasil.

Brasil. 2016. Conselho Nacional de Saúde, Resolução N 510, de 07 de Abril de 2016. Diário Oficial da União, Brasília, Brasil.

Bailey KD. 1982. Methods of social research. Free Press, Nueva York, U.S.A.

Chaves EMF, Barros RFM. 2012. Diversidade e uso de recursos medicinais do carrasco na APA da Serra da Ibiapaba, Piauí, Nordeste do Brasil. Revista Brasileira de Plantas Medicinais 14(3):476-486.

Chaves EMF, Morais RF, Barros RFM. 2017. Práticas alimentares populares com o uso de plantas silvestres: potencial para minimizar a insegurança nutricional no semiárido do Nordeste do Brasil. Gaia Scientia 11(2):287-313.
Emperaire L. 1983. La caatinga du Sud-est du Piaui (Brésil): Étude Ethnobotanique. Éditions Recherche sur les civilisations, París.

Filho ICF, Bomfim BLS, Farias JC, Vieira FJ, Barros RFM. 2017. Pau-D' Arco-roxo (Handroanthus impetiginosus (Mart. ex DC.) Mattos): Conhecimento e uso madeireiro em comunidades rurais do Nordeste do Brasil. Gaia Scientia 11(2):57-70.

Hernández-Xolocotzi E. 1979. El concepto de Etnobotánica. En LA ETNOBOTÁNICA: tres puntos de vista y una perspectiva. Editado por A Barrera, Instituto de Investigaciones sobre Recursos Bióticos A.C., Xalapa, Veracruz, México, Pp. 13-18.

Hurrell JA, Albuquerque UP. 2012. Is ethnobotany an ecological science? Steps towards a complex ethnobotany. Ethnobiology \& Conservation 1(4):116.

IBGE. 2010. Base de Datos de Instituto Brasileiro de Geografia e Estatística: Cidades. Disponive en: http://cidades.ibge.gov.br/painel/painel.php?codmu n=220200 Acceso em 20 Dez 2018.

Jacomine PKT. 1986. Levantamento exploratório reconhecimento de solos do Estado do Piauí. EMBRAPA-SNLCS/SUDENE-DRN, Rio de Janeiro, Brasil.

Martin GJ. 1995. Ethnobotany: a methods manual. Chapman and Hall, Londres, U.K.

Medeiros RM. 2004. Estudo agrometeorológico para o estado do Piauí. Sema, Teresina.

Morin E. 1980. L'unidualité de l'homme. En Philosopher. Editado por C Delacampagne, R Maggiore. Fayard, París, Pp.41-49.

Ramirez CR. 2007. Etnobotánica y la Pérdida de Conocimiento Tradicional en el Siglo 21. Ethnobotany Research and Applications 5:241-244.

Santos LL, Vieira FJ, Nascimento LGS, Silva ACO, Santos LL, Sousa GM. 2014. Techniques for Collecting and Processing Plant Material and Their Application in Ethnobotany Research. En Methods and Techniques in Ethnobiology and Ethnoecology. Editado por UP Albuquerque, LVFC Cunha, RFP Lucena \& RRN Alves. Springer, Nueva York, U.S.A, Pp. 161-173.

Silva PH, Oliveira YR, Abreu MC. 2018. Entre símbolos, mistérios e a cura: plantas místicas dos quintais de uma comunidade piauiense. Gaia Scientia 12(1):1-16.

Siqueira JIA. 2018. Cuentos en Etnobiología como Estrategia de Valorización y Rescate de la Memoria Biocultural. Ethnobotany Research and Applications 17(4):1-3.

Siqueira JIA, Lemos JR. 2016. Conhecimento dos quintais agroflorestais na comunidade Franco, 
Cocal, Piauí. En XXIV SEMINÁRIO DE INICIAÇÃO CIENTÍFICA - UFPI, 2016, Teresina, Piauí, Brasil. Livro de.Resumos.. Teresina, Piauí: EDUFPI, 2016, Pp. 1-3. Recuperado de: http://sis.ufpi.br/25sic/documentos/resumos/modalid ade/vida/Jorge Izaquiel Alves de Siqueira.pdf Acceso em 20 Dez 2018.

Siqueira JIA, Chaves EMF, Lemos JR. 2017. Ethnobotanical Study on The Use Medicinal Plants in Agroforestry Backyards in The Environmental Protection Area of The "Serra da Ibiapaba", Northeastern Brazil. Em Medicinal Plants: Production, Cultivation and Uses. Editado por A Mathias, N Laisné. Nova Science Publishers, Nueva York, U.S.A., Pp. 211-230.

Vieira-Filho MAM, Siqueira JIA, Sousa RS, Lemos JR. 2018. Diversidad biocultural asociada al uso actual de plantas medicinales en una comunidad rural en el litoral piauiense (Noreste de Brasil). Ethnoscientia 3:1-13. 